\section{Forensic Pathology}

SIR,--I refer to your report in the Journal (April 27, p. 1151) giving an account of Professor C. J. Polson's paper at the recent international conference which I attended in London. His suggestion that there should be some form of national forensic pathology service is not entirely new, and I think most pathologists would agree that the cover for this work in the country as a whole is rather uneven.

Very considerable advances have been made in the quality and availability of pathological services since 1948 , and there are now many more consultant pathologists in the hospital service. These changes have resulted in a better over-all standard of coroners' necropsies in most areas, and the suggestion made in Professor Polson's plan that ultimately this work should be taken away from hospital pathologists should be resisted as undesirable and impracticable. The large majority of these necropsies (perhaps $95 \%$ ) are matters of pure morbid anatomy and intelligent interpretation and fully within the competence of the hospital pathologist. They are in fact best performed by doctors who are also dealing with hospital necropsies, and in my opinion it would be a retrograde step to set up a new special group of pathologists dealing only with coroners' necropsies and entirely divorced from hospital and clinical work.

I suggested in my presidential address to the Association of Clinical Pathologists in $1961^{1}$ that outside London and a few of the larger cities which require special consideration the whole coroner autopsy service could be based on hospitals. There are now many joint user arrangements of mortuaries between the hospital service and the local authority, and these could well be extended with the saving of the pathologists' time and the avoidance of unnecessary duplication of buildings.

A two-tier structure should be considered: (a) routine coroners' necropsies to be done by the hospital pathologists, and $(b)$ the investigation of murder, manslaughter, and other cases involving serious criminal proceedings to be done by special forensic pathologists, one or more of which would be attached to each forensic science laboratory. The hospital pathologist could at any stage call in the specialist if he found a case to be outside his experience or beyond his proper competence.

Many pathologists will support me in thinking that these matters are getting a little out of balance, and that widening the gulf between pathology and forensic pathology is to be deplored. There is certainly a place for the specialist, and there is need for more training of the hospital pathologist in forensic pathology, but I see no justification for a new service on the lines suggested. -I am, etc.,

$$
\begin{aligned}
& \begin{array}{l}
\text { Department of Pathology, } \\
\text { Royal Devon and Exeter Hospital, }
\end{array} \\
& \text { Exeter, Devon. } \\
& \text { REFERENCE } \\
& \text { ' Smith, G. S., Med. Sci. Law, 1962, p. } 244 .
\end{aligned}
$$

\section{Rickets in Immigrant Children in London}

Sir,--I found the article by Drs. P. F. Benson, C. E. Stroud, N. J. Mitchell, and A. Nicolaides (April 20, p. 1054) of particular interest, as Dr. J. D. Gray and I had investigated the problem of early diagnosis of rickets at Belgrave Hospital for Children over a period of two and a half years from 1946 to 1948 . Our patients must have been drawn from an area of London which overlaps that described in the present paper, but in our series there were no West Indian children, as the investigation was carried out before immigration had come into vogue. In five years the paediatric departments of Guy's and King's College Hospitals discovered 16 children under $3 \frac{1}{2}$ years with florid rickets. In our series ${ }^{1}$ three cases of severe rickets were found in approximately half that time, the serum alkaline phosphatases being between 80 and $220 \mathrm{King}$-Armstrong units. We were particularly interested in confirming the diagnosis in suspected cases of rickets before bone deformities and radiological changes left no room for doubt about the clinical entity-for example, in infants and children showing non-specific symptoms and signs such as irritability, poor muscle tone, an unexpectedly large anterior fontanelle, etc. Forty-six children under $3 \frac{1}{2}$ years were found with a serum alkaline phosphatase raised above our maximum normal level of $20 \mathrm{~K}$.-A. units. (Fiftysix controls gave an average of $17 \mathrm{~K}$.-A. units with a spread of 11-29 units.) A serum alkaline phosphatase of $30-40 \mathrm{~K}$.-A. units was commonly found in children who presented with symptoms but no conclusive physical signs.

In the paper by Dr. Benson and his colleagues each child was considered to have florid rickets, and the serum alkaline phosphatase was more than 45 units in all except two instances. At the same time they found that the calcium and phosphorus levels were frequently within normal limits, once again confirming the observations made by Barnes et al. ${ }^{2}$ that the serum alkaline phosphatase is a much more reliable indication of the activity of the disease.

With specific therapy in the form of large doses of vitamin $D$ it is usual for the serum alkaline phosphatase level to fall steadily, but transient increases have been noted by several observers, ${ }^{34}$ and occurred in four out of 20 of our cases in whom serial estimations were made. I should be interested to know whether this phenomenon was seen among any of the children in this series recorded by Guy's and King's College Hospitals, and also if the authors can give any information regarding the numbers of children they have seen with doubtful or suspected rickets where the serum alkaline phosphatase has been in the order of 25-40 K.-A. units.

Finally, Dr. Benson and his colleagues have given a timely reminder that there are children in the United Kingdom still who are in need of, but are not receiving, the benefits that the State has provided for them, owing largely to the ignorance and apathy of their parents.I am, etc.,

Barcombe, Sussex.

F. Stephen Carter.

REFERENCES

${ }^{1}$ Grav, J. D., and Carter, F. S., Arch. Dis. Childh., 1949, 24.

= Barnes, D. J., Kaucher, M., and Munks, B., Amer. J. Dis. Child., 1946, 71, 622.

- Josefsson, E., Ann. Paediat. (Basel), 1941, 157, 169.

4 Yieh and Wissler, H., ibid., 1939, 152, 348.

\section{Obliterative Pulmonary Hypertension}

SIR,-During recent months there has been a marked increase in the volume of papers and correspondence in the literature on this and related subjects. The amount of interest which is now being directed to this disease would suggest that either it is becoming more common or that its existence as an entity is more widely appreciated. I believe the latter, at least, to be true, but am also 